\title{
Don't turn your back on the symptoms of psychosis: a proof-of-principle, quasi-experimental public health trial to reduce the duration of untreated psychosis in Birmingham, UK
}

\author{
Charlotte Connor ${ }^{1,2^{*}}$, Max Birchwood ${ }^{3,4}$, Colin Palmer ${ }^{1}$, Sunita Channa ${ }^{1}$, Nick Freemantle ${ }^{5}$, Helen Lester ${ }^{6}$,
} Paul Patterson ${ }^{2,7}$ and Swaran Singh ${ }^{8}$

\begin{abstract}
Background: Reducing the duration of untreated psychosis (DUP) is an aspiration of international guidelines for first episode psychosis; however, public health initiatives have met with mixed results. Systematic reviews suggest that greater focus on the sources of delay within care pathways, (which will vary between healthcare settings) is needed to achieve sustainable reductions in DUP (BJP 198: 256-263; 2011).

Methods/Design: A quasi-experimental trial, comparing a targeted intervention area with a 'detection as usual' area in the same city. A proof-of-principle trial, no a priori assumptions are made regarding effect size; key outcome will be an estimate of the potential effect size for a definitive trial. DUP and number of new cases will be collected over an 18-month period in target and control areas and compared; historical data on DUP collected in both areas over the previous three years, will serve as a benchmark. The intervention will focus on reducing two significant DUP component delays within the overall care pathway: delays within the mental health service and help-seeking delay.

Discussion: This pragmatic trial will be the first to target known delays within the care pathway for those with a first episode of psychosis. If successful, this will provide a generalizable methodology that can be implemented in a variety of healthcare contexts with differing sources of delay.
\end{abstract}

Trial registration: http://www.controlled-trials.com/ISRCTN45058713

Keywords: Public mental health campaign, First-episode psychosis, Early detection, Duration of untreated psychosis, Youth mental health

\section{Background}

International studies have shown that the average length of time from the onset of psychotic symptoms to first treatment (duration of untreated psychosis; DUP) ranges between 364 and 721 days [1] with recent meta-analyses reporting an association between long DUP and poor outcome at 6 and 12 months, for both symptoms and quality of life. Drake et al. [2] suggest that the point at

\footnotetext{
* Correspondence: c.s.connor@bham.ac.uk

'CLAHRC, Birmingham \& Solihull Mental Health Foundation Trust, 66-68 Hagley Road, Birmingham B16 8PF, UK

${ }^{2}$ School of Psychology, University of Birmingham, Edgbaston, Birmingham B15 2TT, UK

Full list of author information is available at the end of the article
}

which DUP exceeds three months, defines a critical point after which the likelihood of poorer outcome begins to increase, and several studies indicate that accessing treatment within the first 6 months of onset is a key indicator of outcome, specifically in terms of treatment response [3-8].

Evidence for the efficacy of initiatives to reduce DUP, however, is mixed [9]; the 'TIPS' study in Norway has had the greatest success. Their prospective trial in a defined health care region, incorporating the introduction of an early detection program alongside a public health awareness campaign, achieved significant results in comparison with parallel health care areas without an

\section{Biomed Central}


early detection program. DUP was significantly shorter and associated with better clinical status and reduced suicide risk at baseline and negative symptoms at 12 months, with positive effects on clinical and functional status maintained at 5 year follow-up [10]. However, similar public health initiatives in Australia [11] and Canada [12] have failed to demonstrate any impact on DUP.

Implementation of a TIPS style intervention in UK healthcare settings, however, may prove ineffective as the care pathway delays experienced by young people with first-episode psychosis in UK may not be directly comparable to those experienced in Norway. Rogaland County is a dispersed population centred around the predominantly Caucasian (95\%) city of Stavanger [13]; approximately $60 \%$ of the population living in urban areas [14]. In contrast, Birmingham, UK is the second most populous city in Britain $(1.05 \mathrm{~m})$ and the 'youngest city in Europe' with $40 \%$ of its population under the age of 20. It has a high degree of cultural and religious diversity, including 68\% White British residents, 20\% residents of Asian or Asian British heritage and 7\% Black or Black British, and includes the highest number of residents from the Muslim faith in any UK local area for whom help-seeking can include imams at the family mosque; indeed, our recent study showed that religious construction of psychosis is common [15].

In the UK, the widespread adoption of early intervention in psychosis teams (EIS) have not led to a reduction in DUP [16,17]; this is, perhaps, not surprising since these teams are not resourced or equipped with any community focused early detection function. Birmingham, UK, was the setting of the first early intervention service in the UK, yet despite this it continues to experience long DUP [18]. Our cluster randomized trial to improve early detection of psychosis focusing on primary care [16] did not achieve reductions in DUP; further analysis revealed that the main sources of delay occurred elsewhere in the care pathway, in particular, within mental health services themselves and in help-seeking delay ${ }^{16 ; 18}$. A recent systematic review of interventions to reduce DUP [1] concluded that greater focus on the sources of delay within care pathways, (which will vary between healthcare settings) is needed to achieve sustainable reductions in DUP.

Recent data from the UK National EDEN study [19] has confirmed that there are two primary sources of delay: delay in help-seeking among both patients and carers and delays within mental health services. The first referral point to mental health services was found to have the greatest impact on DUP: where the first point of contact was for acute crisis (admission, home treatment), delay within the mental health service was low; where access was via a Community Mental Health Team
(CMHT), delays were greatly extended. These findings suggested that whilst improvements in help-seeking behavior are necessary, significant improvements within mental health services themselves would be essential to reduce DUP. In Birmingham, as part of the present study, a youth access pathway into the mental health service has been developed within the CMHT [20], providing a single referral point and ensuring that first episode cases of psychosis are managed in a youth sensitive framework and guarantee direct access to the specialised service.

\section{Hypothesis}

The primary hypothesis to be tested is whether implementation of a psychosis public health campaign in addition to the youth access pathway for first episode psychosis, will significantly reduce DUP.

\section{Methods}

\section{Design}

This is a quasi-experimental, proof-of-principle prospective trial comparing an intervention area in the south of the city, to the non-intervention remainder of the city.

Incident cases of first episode psychosis from these areas will be determined and their DUP and care pathways ascertained over the following 18 months. We also benefit from recent historical DUP data (National EDEN) [19] for both target and control areas.

\section{Sampling}

Birmingham is served by a single mental health service, which served as the 'blueprint' for the Government's National Service Framework for Mental Health [21]; it has a number of community services including Home Treatment and Assertive Outreach teams, including welldeveloped early intervention services for first episode psychosis which were the forerunner of such services across England. It is the second most populous city in Britain with a high degree of cultural and religious diversity and is ranked third most deprived core city in England [22]. Population and ethnic profile of the intervention and control areas [23], together with the number of new cases in the previous 12 months, is shown in Table 1.

\section{Ethical approval}

The trial is sponsored by Research and Innovation department at Birmingham \& Solihull Mental Health Foundation Trust. Advice was sought from the National Research Ethics Service for the NHS. This public health trial falls outside of the requirements for formal approval as: no consent or recruitment of service users is required; no identifiable data will be specifically collected or used for evaluation; and the only data to be used will be 
Table 1 Socio-demographic profile of intervention and control areas

\begin{tabular}{lcc}
\hline & Population & Ethnic profile \\
\hline Intervention Area & 308,150 & $85 \%$ White British \\
& & $8 \%$ Asian \\
& & $3 \%$ Black \\
Control Area & 632,427 & $62 \%$ White British \\
& & $26 \%$ Asian \\
& $8 \%$ Black \\
\hline
\end{tabular}

anonymised DUP data and number of incident cases, both of which are routinely collected for all clients entering the specialist Early Intervention Service (for first episode psychosis) as part of their initial assessment.

\section{The intervention}

\section{Context and theoretical framework}

The 'Precede-Proceed' public health model framework [24] has provided the foundation for this study using assessments of context and setting to inform and guide the development and implementation of the intervention. This will ensure a responsive, stratified 'knowledge-transfer' approach is applied to reducing DUP. This framework is further underpinned by two theoretical models of health behaviour change addressing both cognitive and contextual determinants; the Trans-theoretical/Stages of Change model [25] and the MINDSPACE framework [26]' the latter arising from behavioural economics, widely employed by UK policymakers [27].

Initial findings from the 'Precede' phase of our programme have helped us clarify the likely reasons for delay in care pathways and enabled comprehensive assessment, planning, piloting and target-setting [18]. Patient and public involvement was a fundamental aspect of this preceding phase, involving discussion and consultation with an advisory board comprising of young people and users of the mental health services.

The 'Proceed' phase now focuses directly on implementation and evaluation of the intervention, but will, nevertheless, continue to incorporate comprehensive and iterative feedback at each stage to determine the most successful methods of improving help-seeking and youth care pathways.

\section{Care pathway interventions}

\section{Improving help-seeking.}

The aim of this component of the intervention is to improve the help-seeking of young people and their carers, who are experiencing symptoms of first-episode psychosis through implementation of a psychosis awareness campaign including information about when, where and how to seek help. Individuals are encouraged to access a helpline and a bespoke website.
The campaign was launched in January 2012 and will run for 18-months. Campaign staff, will be active at the heart of the community, in local shopping centres and supermarkets, at employment centres and community events and will work closely with youth and community groups. All campaign material bears the psychosis campaign slogan, 'Don't turn your back on the symptoms of psychosis', the website link (www.youthspace.me/psychosis) and the information line number.

The campaign will be broken into 6 three-month stages. Each stage comprising of the following elements:

i. Advertising in high use settings. Campaign posters will be displayed in a variety of settings, including local bus services and shopping centres. Smaller leaflets and postcards will be routinely distributed across the target areas including supermarkets, employment offices, community and youth groups, leisure centres, coffee shops and fast-food outlets. Informed by our pathfinder studies, the poster themes focus specifically on young people, their friends and parents/carers.

ii. Leaflet drops Leaflets drops to homes on several large social housing estates in hard-to-reach areas which have no central shopping centre, high street or supermarket.

iii. Advertising in community press Posters and articles about psychosis, featuring interviews with clinicians and service users, will appear in community newspapers and magazines at regular intervals throughout the campaign; these monthly, bi-monthly and quarterly newspapers and magazines are delivered free to homes in the target areas.

iv. Advertising on community websites Posters, on-going campaign information and articles about psychosis will be routinely posted on 6 community websites and 10 library web-pages in the target area.

v. Attendance at community events Campaign volunteers and staff will attend a variety of community and music events and also attend student events at Universities and colleges in the intervention area.

vi. Promotion of www.youthspace.me/psychosis Launched in early 2011, our website offers advice, resources, signposting, educational films, blogs and social media access for young people, families/carers and those who work alongside young people on all aspects of mental health and well-being. For the purposes of the psychosis campaign, a direct link to the psychosis specific page of the website will be 
Table 2 Number of incident cases and their DUP: August 2011 - August 2012

\begin{tabular}{lccccc}
\hline & $\begin{array}{c}\text { New } \\
\text { cases }\end{array}$ & $\begin{array}{c}\text { DUP (mean; } \\
\text { median; sd) }\end{array}$ & $\begin{array}{c}\text { Delay in help-seeking } \\
\text { (mean; median; sd) }\end{array}$ & $\begin{array}{c}\text { Delay within mental health services } \\
\text { (mean; median; sd) }\end{array}$ & $\begin{array}{c}\text { Delay in accessing EIS } \\
\text { (mean; median; sd) }\end{array}$ \\
\hline $\begin{array}{l}\text { Intervention } \\
\text { Area }\end{array}$ & 88 & $293 ; 38(867.1)$ & $50 ; 0(131.6)$ & $211 ; 30(481.4)$ & $443 ; 56(930)$ \\
Control Area & 250 & $264 ; 58(539)$ & $114 ; 3(271.4) 113$ & $213 ; 22(511.9)$ & $323 ; 105(560.8)$ \\
\hline
\end{tabular}

promoted, providing a variety of information about psychosis, the benefits and importance of early helpseeking, and where to go to seek help.

vii. The Psychosis Information line

A psychosis information line features on all campaign material, offering an alternative way of help seeking for those who would rather speak to trained advisors about their concerns or for those who have no access to a computer. A similar line was utilised in the TIPS study. Its main function will be to provide callers with information about psychosis, send out information packs and facilitate access to a clinician for further assessment where appropriate.

viii.Youth Advisors

Youth advisors will regularly update the campaign with photographs, video footage and blogs by those who have experienced mental health issues and ensure we utilise timely and age appropriate creative strategies to engage with young people.

ix. Psychosis Awareness Training

We will collaborate with Emergency Services, youth, community, employment and education agencies to provide psychosis awareness training; this will enable greater outreach into the community and create a broad network of organisations and individuals through which the campaign can be targeted.

2. Youth mental health care pathway.

A youth access care pathway was developed operating alongside existing CMHTs in the intervention area and provides direct referral channels and immediate assessments for all young people presenting to primary care with mental health difficulties aged 14-25 [20]. The service was established to improve the care pathways of young people ensuring that all cases of first episode psychosis have direct access to EIS, enabling and maintaining good levels of engagement with young people from their earliest presentation.

\section{Inclusion and exclusion criteria}

All new cases of first episode psychosis accepted by the Early Intervention in psychosis Service.

Patients considered at ultra-high risk of psychosis, using the Comprehensive Assessment of At Risk Mental State (CAARMS) [28] are excluded. Since this is a pragmatic trial focussing on reducing DUP in patients managed within an EIS, there will be no other exclusions.

\section{Measures}

DUP is routinely calculated for all clients with a first episode of psychosis at entry into EIS services, employing a combination of retrospective assessment of positive and negative symptoms of psychosis (SCI-PANSS) [29], Pathways to Care interview [30] and electronic care records. This is based on the method described by Larsen et al [10] and used in our research [18].

The Pathways to Care interview follows the method of Gater et al. [30] in which systematic information is gathered from direct interview and electronic care records about the source, sequence and timing of helpseeking by patients and their families, including helpseeking contacts, the main problems presented and treatments offered. This included the sequence and duration of contacts within the mental health service. We also documented any mental health service contact prior to the formal onset of psychosis. These data were synthesised onto visual 'route timelines'; presenting the sequence of help-seeking contacts, referrals made, diagnoses offered, treatment provided and outcomes.

All DUP interviews are conducted by graduate research psychologists, who have satisfactorily completed five DUP calculations, reproducing scores pre-defined by trainers [18]. Each interview takes approximately 1 hour to complete and research staff undergo 6-monthly checks on their assessment reliability, consisting of submission of five timelines and DUP calculations to DUP co-ordinators for concordance and standardisation of calculation. Continual feedback and assistance from co-

Table 3 Confidence Intervals for the target area based on predicted increase in referral rate

\begin{tabular}{ccc}
\hline $\begin{array}{c}\text { Yearly referral rate } \\
\text { increase }\end{array}$ & $\begin{array}{c}\text { Predicted confidence } \\
\text { Interval (+/-) }\end{array}$ & Cl width \\
\hline 30 & 218 & $90-526$ \\
40 & 187 & $121-495$ \\
50 & 166 & $142-474$ \\
60 & 151 & $\mathbf{1 5 7 - 4 5 9}$ \\
70 & 139 & $169-447$ \\
80 & 130 & $178-438$ \\
90 & 123 & $185-431$ \\
100 & 116 & $192-424$ \\
\hline
\end{tabular}


ordinators was maintained throughout data collection to ensure inter-rater reliability.

\section{Primary outcome \\ DUP}

We hypothesise that our psychosis awareness campaign, in combination with the introduction of the youth focused clinical access team, will significantly reduce DUP.

\section{Secondary outcome \\ Referral rates}

We also predict an increase in referrals of young people diagnosed with a psychotic disorder from the intervention area into EIS.

Table 2 shows baseline DUP and component delays for incident cases in between August 2011 and August 2012.

\section{Primary analysis}

DUP and referral rates for intervention area compared to the control area will be monitored and evaluated every three months throughout implementation and at the culmination of the intervention ( 2 year period). In the TIPS study, despite DUP being relatively short in both areas (with a combined median of 10 weeks), DUP was significantly reduced in the intervention area, reduced to a median of 5 weeks compared with 16 weeks in the control area [31]. In this proof-of-principle trial, we make no a priori assumptions about effect size since the methodology and setting is unique. The key outcome of this trial will be an estimate of the effect size, which will inform a definitive trial. The confidence intervals for different levels of increase in the number of new referrals in the target area are shown in Table 3.

\section{Secondary analysis \\ Website visits}

We also predict there will be an increased number of online visits to our website www.youthspace.me/psychosis. The website went live in September 2011. Website visits will be monitored on a monthly basis before, during and after the intervention.

\section{UK benchmark DUP data}

The trial benefits from extensive DUP data from UK National EDEN sites in Cambridge, Cornwall, Blackburn, Blackpool, Burnley, Lancaster and Norwich [18].

\section{Discussion}

Although reducing DUP is a UK Department of Health target, there has been no effective strategy for achieving this in the UK. This is the first UK trial attempting to reduce DUP. The ethnic profile of Birmingham, however, is diverse and includes large numbers of inhabitants of Asian and Black heritage, therefore, any findings from this intervention, will be need to be carefully considered in light of this diversity. Our application of the Precede/ Proceed public health model in the design and implementation of the trial, nonetheless, will provide a generalizable methodology that should be applicable to a variety of healthcare contexts with differing sources of delay.

\section{Competing interests}

The authors declare that they have no competing interests.

\section{Authors' contributions}

The trial was designed by the first two authors; all authors read and approved the final manuscript.

\section{Acknowledgements}

Professor Birchwood, Dr Connor, Dr Patterson, C Palmer, S Channa are part funded by National Institute of Health Research CLAHRC (Collaboration for Leadership in Applied Health Research and Care) Birmingham and The Black Country.

\section{Funding}

The trial is funded by the UK National Institute of Healthcare Research and developed within the Collaboration for Leadership in Applied Health Research and Care (CLAHRC) programme for Birmingham and the Black Country.

\section{Author details}

${ }^{1}$ CLAHRC, Birmingham \& Solihull Mental Health Foundation Trust, 66-68 Hagley Road, Birmingham B16 8PF, UK. ${ }^{2}$ School of Psychology, University of Birmingham, Edgbaston, Birmingham B15 2T, UK. ${ }^{3}$ Youth Mental Health, School of Psychology, University of Birmingham, Edgbaston, Birmingham B15 2 $2 T$, UK. ${ }^{4}$ Youthspace Mental Health Service, Birmingham and Solihull Mental Health Foundation Trust, Edgbaston, Birmingham B15 2TT, UK. ${ }^{5}$ Clinical Epidemiology \& Biostatistics, Department of Primary Care and Population Health, UCL Medical School (Royal Free Campus), Rowland Hill Street, London NW3 2PF, UK. ${ }^{6}$ Primary Care, Primary Care Clinical Sciences, School of Health and Population Sciences, Primary Care Clinical Sciences Building, University of Birmingham, Edgbaston, Birmingham B15 2TT, UK. ${ }^{7}$ Youthspace, Birmingham \& Solihull Mental Health Foundation Trust, 66-68 Hagley Road, Birmingham B16 8PF, UK. ${ }^{8}$ Mental Health \& Wellbeing, Medical School Building, Gibbet Hill Campus, University of Warwick, Coventry CV4 7AL, UK.

Received: 3 December 2012 Accepted: 13 February 2013 Published: 22 February 2013

\section{References}

1. Marshall M, Lewis S, Lockwood A, Drake R, Jones P, Croudace T: Association between duration of untreated psychosis and outcome in cohorts of first-episode patients. A systematic review. Arch Gen Psychiatry 2005, 62:975-983.

2. Drake RJ, Haley CJ, Akhtar S, Lewis SW: Causes and consequences of duration of untreated psychosis in schizophrenia. Br J Psychiatry 2000, 177:511-515.

3. Malla AK, Norman RM, Manchanda R, Ahmed MR, Scholten D, Harricharan R, et al: One year outcome in first episode psychosis: influence of DUP and other predictors. Schizophr Res 2002, 54:231-242.

4. Goldman H: Review of general psychiatry. 5th edition. Nowalk: Appleton \& Lange; 2000.

5. Robinson DG, Woerner MG, Alvir JM, Geisler S, Koreen A, Sheitman B, et al: Predicors of treatment response from a first episode of schizophrenia or schizoffective disorder. Am J Psychiatry, 156:544-549.

6. Carbone S, Harrigan S, McGorry PD, Curry C, Elkins K: Duration of untreated psychosis and 12-month outcome in first-episode psychosis: the impact of treatment approach. Acta Psychiatr Scand 1999, 100:96-104.

7. Linszen D, Dingemans $P$, Lenior M: Early intervention and a five year follow up in young adults with a short duration of untreated psychosis: ethical implications. Schizophr Res 2001, 51:55-61. 
8. Sheitman BB, Lee H, Strauss R, Lieberman JA: The evaluation and treatment of first-episode psychosis. Schizophr Bull 2006, 23:653-661.

9. Lloyd-Evans B, Crosby M, Stockton S, Pilling S, Hobbs L, Hinton M, et al: Initiatives to shorten duration of untreated psychosis: systematic review. Br J Psychiatry 2011, 198:256-263.

10. Larsen TK, Melle I, Auestad B, Haahr U, Joa I, Johannessen JO, Opjordsmoen S, Rund BR, Rossberg J, Simonsen E, VaPSMglum P, Friis S, McGlashan T: Early detection of psychosis: positive effects on 5-year outcome. Psychol Med 2010. doi:10.1017/S0033291710002023. FirstView Article. Published online by Cambridge University Press.

11. Krstev H, Carbone S, Harrigan SM, Curry C, Elkins K, McGorry PD: Early intervention in first-episode psychosis-the impact of a community development campaign. Soc Psychiatry Psychiatr Epidemiol 2004, 39(9):711-9.

12. Malla A, Norman R, Scholten D, Machanda R, Mclean T: A community intervention for the early identification of first episode psychosis impact on duration of untreated psychosis (DUP) and patient characteristics. Soc Psychiatry Psychiatr Epidemiol 2005, 40(5):337-344.

13. Statistics Norway. http://www.ssb.no/english (accessed Feb 2012).

14. Office of National Statistics. http://www.ons.gov.uk/ons/index.html.

15. Rashid S, Copello A, Birchwood M: Muslim faith healers' views on substance misuse and psychosis. Ment Health, Relig \& Cult 2012, 15(6):653-673.

16. Lester HE, Birchwood M, Freemantle N, Michail M, Tait L: REDIRECT: cluster randomised controlled trial of GP training in first-episode psychosis. $\mathrm{Br} J$ Gen Pract 2009, 59(563):183-90.

17. Singh SP: Early Intervention in Psychosis. Br J Psychiatry 2010, 196:343-345.

18. Brunet $K$, Birchwood M, Lester $H$, Thornhill K: Delays in mental health services and duration of untreated psychosis. Psychiatrist 2007, 31:408-410.

19. Birchwood M, Lester H, McCarthy L, et al: The UK National evaluation of the development and impact of early intervention services (The National Eden Studies): Study rationale, design and baseline characteristics. Early Interv Psychiatry 2013, eScholar ID:186280. doi:10.1111/eip.12007.

20. McGorry P, Bates T, Birchwood M: Designing Youth Mental Health Services for the 21st century: Examples from Australia, Ireland and the UK. British J Psychiatry, 202:s30-40.

21. Department of Health: UK National Mental Health Service Framework. London: 2001

22. Index of deprivation: An analysis of Birmingham Local Statistics. 2010. http:// www.birmingham.gov.uk/birminghameconomy.

23. Indices of Multiple Deprivation. West Midlands Public Health Observatory; 2007. http://www.wmpho.org.uk/localprofiles/metadata.

24. Green L, Kreuter M: Health program planning: An educational and ecological approach. 4th edition. New York, NY: McGraw-Hill; 2005.

25. Prochaska J, DiClemente CC: Stages and Processes of self-change of smoking: Toward an integrative model of change. J Consult Clin Psychol 1983, 51(3):390-395.

26. Dolan P, Hallsworth M, Halpern D, King D, Metcalfe R, Vlaev I: Influencing behaviour: The mindspace way. J Econ Psychology 2012, 33:264-277.

27. Office C: Applying behavioural insight to health. London: HM Government; 2011.

28. Yung A, Phillips L, Simmons MB, Ward J, Thompson K, French P, et al: CAARMS: Comprehensive Assessment of At Risk Mental States. Melbourne, Australia: The PACE Clinic; 2006

29. Kay SR, Fiszbein A, Opler LA: The Positive \& Negative Syndrome Scale (PANSS) for Schizophrenia. Schizophr Bull 1987, 13(2):261-275.

30. Gater R, de Almeida e Sousa B, Barrientos G, Caraveo J, Chandrashekar CR, Dhadphale $M$, et al: The pathways to psychiatric care: a cross-cultural study. Psychol Med, 21:761-774

31. Melle I, Larsen T, Haahr U, Friis U, et al: Reducing the duration of untreated first-episode psychosis. Arch Gen Psychiatry 2004, 61:143-150.

\section{Submit your next manuscript to BioMed Central and take full advantage of:}

- Convenient online submission

- Thorough peer review

- No space constraints or color figure charges

- Immediate publication on acceptance

- Inclusion in PubMed, CAS, Scopus and Google Scholar

- Research which is freely available for redistribution 